FIBRO-CYSTIC DISEASE OF THE TESTIS. BY SAMUEL OSBORN, F.R.C.S.

The following case of fibrocystic disease of the testis, in which castration was performed, is of especial interest when taken in connexion with those cases lately published by Mr. Rivington.

J. B-, aged thirty eight, a carpenter, and a married man with eight children, the youngest being three months old, all of whom are healthy, first came under my notice in the early part of February, with fibro-cystic disease of the right testicle. He had never bad gonorrhoa, syphilis, or any illness since childhood. One brother died of phthisis at the age of thirry-three. Twelve years ago he fell upon a joist, burting his back and both testes; the latter became swollen, but in a month's time resumed their normal size. Five years subsequently a lump appeared at the lower part of the right testicle, which gradually enlarged to the size of a small walnut; it was incised by Mr. Wood, of King's College Hospital, bled freely and soon disappeared. In 1874 he was in St. Thomas's Hospital, with hydrocele of the cord on the right side; it was twice tapped, and at the second tapping injected with iodine. Eighteen months ago he first noticed a hard lump in the centre of his right testicle, which grew slowly, and after nine months was about the size of a walnut, becoming more painful as it grew; the next six months it grew more rapidly, but during the last, three it has been stationary. Pain during the last fortnight, has been more severe. He has been of greater excitability since the testicle has been affected, and alwass suffered more pain when he did not have frequ+nt connexion (, $\mathrm{n}$ this account I believe the testicle to bave been still of tecundative power, from the pain, fulness, \&o., which were relieved by cuition). Seven months ago a trocar was thrust into the testicle from below, and subsequently a projecting knob grew from the testicle at the point of puncture. The testicle had been strapped for three weeks; and subsequently he had been treated internally with mercury and iodide of potassium, all without relief.

When first seen the right testicle was abuut the size of a small orange, with a projecting knob the size of a small walnut at the lower part. Cord free and not enlarged. Pain of a dragging character, occasionally shooting up the groin in to the small of the back, was increased when standing or walking from the pendulous position of the testicle. The testicle itself was especially tender at the top and outer side; when pressing on the epididymis be experienced very sharp pain up the groin. The cord-like feel of the epididymis be thought was a vein, as it was knotted, and became lost in the testicle above and below, being thicker at some times than at others, and smaller after connexion. Castration was recommended, and Mr. Sydney Jones kindly admitted him into St. Thomas's Lospital, to whom I am indebted for the following notes of the case; also, through his having placed at my disposal the removed testis, I am able to give the subjoined pathological report.

He was admitted into hospital on March 6th, and on the following day the testicle was punctured by a trocar and cannula, and a small quantity of a thin, glairy, yellow fluid withdrawn, which, under the microscope, showed white granular corpuscles, but no sperm-cells.

On March $10 \mathrm{~kb}$ Mr. Sydney Jones performed castration, having first cut gradually down upon the testicle, and found that the tunica vaginalis was quite healthy, and that it was undoubtedly the testicle which was affected. Hæmorrbage from the divided cord was stopped by ligaturing the larger vessels with catgut and twisting the smaller vessels. The wound was closed with sutures, and a drainage-tube placed in the most depending position.

March 11th - $\mathrm{H}$ id very little sleep last night, owing to the pain in his back. No pain in scrotum or groin. No discharge from the wound or drainage-tube. Wound looks bealtby. Temperature normal. Drainage-tube removed, and ice-bag applied.

12th - Pain in back less, and consequently slept better last night. Slight discharge from the wound.
18 h.- Sull shight pain in the back, and some shooting pain in the groin.

27rh.-Feels quite well now. No discharge from the wound nor any pain. He now gets up in the afternoon.

29th.-Wound quite healed, and pat ient left the bospital. On removal the testicle measured three inches in its long diameter, two in hes in its transverse; the greater portion of the external surface was smooth. A small boss about the size of a pea was situted at the upper and outer side, and another, about the size of a small walnut, was attached to the lower part of the testicle by a pedicle in size equal to that of a crowquill, both of which enuld be felt through the scrotum previous to extirpation. The testicle, when cut in half, emitted a peculiar odour, as if partially dec rmposed, and was made up of numerous cysts varying from the size of a millet-seed to that of an ordinary marble; the contents of some of these cysts welling up on the section being made. Epididymis, globus majnc and minor, were perfectly healthy. The tumour had probably sprung from the mediastinum testis and pushed the seminal cones up wards and forwards; and the testicle structure, apparently quite bealthy, was spread out over the front and upper part of the tumour, which was encysted and quite distinct in its capsule from the seminal cones.

The cysts, varying in size, and in some cases multilncular in character, were situated in a fibrous stroma. One of these cysts contained fresh coagulated blood, probably being that cyst which was punctured three days before the operation. Some of the cysts had serous contents; the majority, however, contained a cheesy substance, varying in colour from white to a deep red, and which under the microscope exhibited an indifferent tissue, which, probably, if all,wed to have gone on for a greater length of time, would have assumed the more definite structure of hyaline car. tilage, which was found in some few eysts. No spermatozoa were found in any of the cysts examined.

The projection at the lower part of the testicle was a small cystic tumour attached to the testicle by a peduncle, and was probably a protrusion of a portion of the tumour from the puncture performed seven months back; its being multilocular in character accounted probably for the translucency of this projection when examined by transmitted light two weeks before his admission into hospital. The affection was probably a new growth, and commenced first by a cellular infiltration of the intertubular connective tissue, which, becoming fibrillated, led to an increase of the connective tissue bet reen the tubes of the rete testis; some of the cellular infiltration situated farther from the blondressels breaking down to form the cysts, containing indifferent tissue, which would subsequently have gone on to the formation of a matrix and development of cartilage Probably eysts were also formed by the dilated tubes of the rete testis, owing to the unequal pressure to which they were subjected by the new growth, thus accounting for the occasional presence of cystr lined by a tesselated epithelium as described by Curling.

\section{BRONCHOCELE IN BAXA, BHOOTAN.}

By H. A. CHATHAM GRAT, M.B. EDIN., SURGEON, BRYGAL MEDICAL SERYICE.

IT may be interesting to record some points 'regarding bronchocele in the north-eastern parts of India on the Bhootan frontier. I had the opportunity of observing this affection amongst the Bhooteas when in medical charge of the 18th Regt. N.I., now stationed at Baxa. I hope this paper will prove a supplement to Sir J. Fayrer's article on Bronchocele that appeared in THE LANCET of October 24th and 31st, 1874.

I wish to be very brief and concise, and bence will divide this paper under the following headings:- $(a)$ General geographical and geological features of Baxa. (b) Prevalence of goitre amongst the Bhooteas as compared with the people in the Terai and the plains beyond. (c) Nature of strata from which water is derived.

(a) Baxa is situated in longitude $89 \frac{1}{3}^{\circ}$ on the Bhootan 
frontier, abour 2000 feet above sea-level, sheltered on three sides by bills 400 and 600 feet above level of s'ati $n$; ex. posed to S.W.; opening up a view of the Terai and the level countries of Cooch, Brhar, and Julpigoree; pleasantly cold in winter (temperature $48^{\circ}$ to $66^{\circ} \mathrm{F}$.) ; punkahs not required in bot sease $n$; very damp in rainy months, rainfall 250 to 280 inches per annum; water derived from eprings. Surface composed of boulder-drift; detached masses of sandstone abundant; little granite; some gneiss-quartz rock, principally in veins. The strata consist of mica slate and schist, talcose slate, hornhlende slate, and clayslate. Serpentine is to bu found in the beds of streams.

Malarial fever is not common in $B+8 a$; people suffering from it in the station contract it in the Terai and plains.

(b) There are about 500 Bbooteas who inhabit, the villages around Baxa. It is the exception to see a Bhontea without $a$ bronchocele. The young and aged are affected alike. These tumours may be seen in all stages of growth, from a size just perceptible, to the dimensions of on adult human head. The inbabitants of the villages in the heart of the Terai are comparatively exempt from goitre. In Cooch, Behar, and Julpigoree I saw very little of it.

The Bhooteas are well developed and muscular men and women. They keep very good health and work hard, eat, coarse food, drink any sort of water, whether clear or turbid with organic and inorganic impurities, live in huts raised above the ground, and rear pigs and poultry under them; they never wash their bodies, and do not change their garments until tbe texture rots and drops off. The Bhooteas who do not descend into the plains are free from fever. Thus, under the worst hygienic conditions, they are in good health, do not present the malarial cachexy, and yet it is the exception to find a person not suffering from goitre. The people in the plains are, of course, "depraved in bealth and cachectic;" they live under better bygiene, wash daily, change their clotbes frequently, and eat better food; they, moreover, drink the water drunk by the Bhooteas, but which has gatbered more impurities in its course through the Teral; and yet goitre is not so frequent and general amongst them. Can, then, malaria have much to do with the production of goitre?

(c) The general geological conformation of Baxa has been already given. It is very interesting to compare with this the following table, compiled by Dr. Parkes, from Dr. M'Clellan's work:-

\section{Goitre and Cretinism in Kumaon (Oude).}

Water derived from

Percentage of population affected

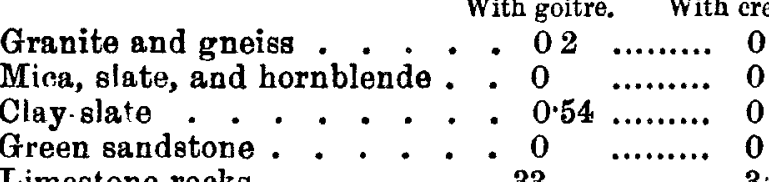

This table gives only 56 per cent. of population as affected by goitre produced by water derived from granite, gneiss, mica, slate, hornblende, and clay-slate. Now, the water drunk by people at Baxa must be derived from nearly all the above-mentioned rocks. At some early part of its course the water might traverse limestone rocks, but of this I bave no definite knowledge. There is no limestone near Baxa; there are some limestone rocks a good way to the west of Baxa and below its elevation. I heard an engineer remark that there is much difficulty in procuring it.

If the spring water that has percolated through the above metamorphic rocks is the cause of the goitre, then it is very strange that the sepoys of the regiment stationed there do not become affected with bronchocele. Dr. Courtuey, of the $38 \mathrm{tb}$ Regt. N I, informed me that when his regiment first arrived at Baxa, he observed slight enlargements of the thyroid gland in some sepoys, and that these swellings disappeared without treatment. After a residence of three years, the men of his regiment left Baxa perfectly free from goitre. During my stay of three months with the 18th Regt. N.I. at Baxa, I carefully watched for signs of enlargement of the thyroid amongst the sepoys, who drank freely of the spring water, but I did not observe even that temporary effect of the water mentioned to me by Dr. Courtney.

In concluding, I wish to point to the fact that magnesia enters largely into the chemical composition of the rocks in and about Baxa. I state this simply as a fact, for I have no theory regarding the causation of goitre.

\section{E L E C T R O - T H E R A P E U T I S.}

\section{BY J. DIXON MANN, L.K.Q.C.P.I.}

\section{II-ON INDUCTION COILS.}

IN order to determine the best form of induction apparatus it will be necessary briefly to explain the theory involved in its construction.

If two straight wires are placed side by side without touching, and a battery-current is transmitted through one, a momentary wave of electricity darts through the other; so long as the battery-current continues to flow, no further effect is produced, but on detaching the battery another impulse is induced in the free wire. It is important to bear in mind that the induced current is never, from the nature of its causation, continuous, but occurs only momentarily at each make and break of battery contact, whence the synonym "interrupted current." The alternate currents thus induced are opposed in direction; on making battery-contact the induced current flows in a contrary direction to the batterycurrent; on breaking battery-contact, the induced current flows in the same direction as the battery-current. The two currents differ also in intensity; the electro-motive force of the current induced by make of battery.contact is much feebler than that induced by break of $\mathrm{c}, \mathrm{n}$ tact. It is considered by many medical electricians, with $w h(m)$ coincide, that the direct induced current only should be used; the method of obtaining a uni-direction-current will presently be described. In the induction coil the wires are insulated, and instead of being straight are wound in spirals round a core of iron wires, the battery or primary wire being next the core, with the secondary superimposed upon it. An additional phenomenon is thereby produced in the primary wire, called the "extra" current, which is caused partly by the inductive influence of the spirals on eacb other, and partly by the magnetic induction of the core of iron wires; the "extra" current constitutes what is known therapeutically as the "primary" current.

The electro-motive force and the "quantity" of a coil are respectively in direct proportion to the length and to the transverse section of the wire; that is, the greater the number of spirals the greater the intensiky of the current, and the thicker the wire the greater the quantity. In the induction coils used by physicists the secondary wire is as thin as possible, and is of great lengtb, intensity being mostly required. For medical purposes quantity is equally necessary, as beyond a certain limit intensity is mischlevous, and even dangerous; therefore a proportionally shorter and thicker wire should be used. In order still further to increase the "quantity" the "extra" current of the primary wire should be included with the secondary circuit by connecting the initial end of the secondary to the primary wire; or, what comes to the same thing, the coil should consist of one con. tinuous wire, the battery circuit being made through the first two layers, which are equivalent to the primary wire in the ordinary form of coil, and are therefore much thicker than the rest of the wire in order to reduce the resistance to a minimum. Duchenne attributed different physiological effects to the primary and to the secovdary currents, but there can be no douht that the results he obtained were due simply to the difference in the electro-motive force of the two currents, and not to any special properties possessed by one or the other. Another advantage is derived by taking up the "extra" current along with the secondary circuit ; in ordinary coils, where this is not done, the spark of the "extra" current causes rapid oxidation of the platinum contacts of the vibrator, and is a frequent source of failure in the working of the coil ; this, to a great extent, is obviated by absorbing the "extra" current in the general circuit.

The intensity of the induced current is regulated in a 